\title{
Applicability of the modified diatomite for treatment of wastewater containing heavy metals
}

\author{
Dmitry Boriskov ${ }^{1}$, Sanya Efremova ${ }^{1}$, Nadezhda Komarova $^{1}$, Elena Tikhomirova ${ }^{2}$, and Aleksey Bodrov ${ }^{1}$ \\ ${ }^{1}$ Penza State Technological University, 440039 Penza, Russian Federation \\ ${ }^{2}$ Yuri Gagarin State Technical University of Saratov, 410054 Saratov, Russian Federation
}

\begin{abstract}
The paper studies various modifications of diatomite, aiming at creating sorbents for wastewater purification from heavy metal ions. Diatomite of the Akhmatovskoe deposit of the Penza region was considered as a raw material. The processes of physical and chemical modification of diatomite were investigated. Adsorption isotherms were constructed, quantitative characteristics of adsorption of copper ions on the surface of modified sorbents were obtained. A chemical modification (acidic and alkaline) is proposed, which results in an increased adsorption capacity for heavy metal ions. The applicability of diatomite for the purification of highly concentrated wastewater containing heavy metals is shown.
\end{abstract}

\section{Introduction}

Modern society faces important ecological tasks prevention of pollution and protection of water bodies from pollution by sewage. These issues can be solved using advanced technologies. The search for new approaches for the purification of metal-containing wastewater is very important. Heavy metal ions (HMII) are the main pollutants in industrial wastewater. Considerable use of HMI in production leads to their accumulation in the environment and poses danger $[1,2]$.

The reuse of treated wastewater can be achieved by several treatment technologies. A review [2] considers the most commonly used technologies for the removal of heavy metals - chemical precipitation, membrane filtration, ion exchange, and coagulation of alum. The paper describes important methods of laboratory studies that are necessary to determine a feasible and convenient wastewater treatment.

The work [3] considers the use of electrocoagulation as an independent technology, as well as in combination with the filtration of oxidizing media to remove arsenic and manganese from the groundwater. Comparative studies showed that utilization of a conventional coagulant led to a decrease in arsenic concentration by an order of magnitude more than when during electrocoagulation.

For the treatment of metal-containing wastewater, adsorption technologies are more promising and costeffective [4]. They have the following advantages: the process simplicity, speed, and suitability for wastewater with moderate and low concentrations of HMI [5]. According to studies [6], sorbents based on biochar have the adsorption capacity for HMI. They are widely used in wastewater treatment due to their properties, namely high porosity, large surface area, affinity for metals, surface modification, stability, recyclability, and safe disposal.

Experimental factors such as $\mathrm{pH}$, adsorbent dosage, contact time, temperature, initial ion concentration, and ionic strength that affect the removal of metal ions were studied in [7]. Various models of adsorption kinetics and adsorption isotherms were discussed using illustrations to gain an understanding of the adsorption procedure.

The results of serial laboratory experiments on enhanced adsorption of HMI in groundwater using sand columns enriched with graphene oxide and modeling of technological processes are presented in [8]. The retention of $\mathrm{Cr}(\mathrm{VI}), \mathrm{As}(\mathrm{III}), \mathrm{Cd}(\mathrm{II})$, and $\mathrm{Pb}(\mathrm{II})$ in the prepared medium was investigated.

The review of works on the technologies for removing HMI ions from effluents indicates its priority in the areas of physical chemistry, in the creation of innovative treatment technologies.

In recent decades, the interest of scientists in the development of new technologies for wastewater treatment has significantly increased [9]. Of exceptional attention is the treatment of wastewaters from galvanic production, which is one of the most significant problems for the aquatic environment due to its high toxicity [10-14].

In modern economic conditions, of high priority are purification methods based on the use of inexpensive local raw materials. So, diatomite has attracted the attention of specialists [1,15-19]. Natural diatomite has a high surface area, which indicates a high adsorption and chemisorption capacity [20,21]. The sorption capacity can be significantly increased by modifying the surface layers, which is confirmed by the literature data $[10,18,20,22,23]$. 
The purpose of this study is to substantiate the possibility of modified diatomite utilization for the purification of wastewater from heavy metal ions.

\section{Materials and methods}

The object of the study is diatomite from the Akhmatovskoe deposit of the Penza region (Russia). Its chemical composition (\%) was determined by infrared spectroscopy: $\mathrm{SiO}_{2}$ (silicon oxide) - 82.4; $\mathrm{Al}_{2} \mathrm{O}_{3}$ (aluminum oxide) - 2.7; $\mathrm{Fe}_{2} \mathrm{O}_{3}-1.8 ; \mathrm{CaO} 1.88 ; \mathrm{MgO}$ 0.91; other impurities - 9.1. In addition to silica, the composition contains crystals of salts of calcium, sodium, iron, aluminum, various organic compounds (9$10 \%)[1,10,22]$.

The diatomite was modified with $1 \mathrm{~N}$ hydrochloric acid; the alkaline activation was performed using $1 \mathrm{~N}$ of $\mathrm{NaOH}$ solution for 1 hour. Then the samples were repeatedly washed with distilled water, neutralized to $\mathrm{pH}$ 7. Further, they were dried at room temperature to the state of an air-dry substance [1,11]. Thermal activation was carried out by heating the native pre-washed and sieved diatomite in a muffle furnace for 3 hours at a temperature of $440-460{ }^{\circ} \mathrm{C}[20,24]$.

Standard solutions of copper ions $(+2)$ were prepared based on $\mathrm{Cu}\left(\mathrm{NO}_{3}\right)_{2}$ nitrate of chemically pure grade. The content of copper ions in standard solutions was 0.067 ; $0.275 ; \quad 5.0 ; \quad 10.0 ; 25.0 ; \quad 50.0 ; 112.7 \mathrm{mg} / \mathrm{l}$. The concentration of copper ions in suspensions was measured by the method of ion potentiometry using a copper ion-selective electrode "ELIS-131 $\mathrm{Cu}^{\prime}$ and a standard ion meter "Expert 001" during daily calibration. The stabilization of the ionic strength was maintained using buffer solutions; the electrode potentials were recorded when the signal drift practically ceased.

The adsorption processes on adsorbents were studied according to the standard technique (and repeated three times). So, $2.0 \mathrm{~g}$ of diatomite was filled by $100.0 \mathrm{ml}$ of a standardized copper-containing solution $\left(\mathrm{C}_{0}\right)$ and stirred on a laboratory apparatus for shaking. The primary readings of the device were taken at the end of contact with the adsorbent $(1 \mathrm{~h} ; 24 \mathrm{~h})$, and, according to the calibration graph, were transformed into concentration units [20]. Adsorption $A$ was calculated by the formula (1):

$$
A=\frac{\left(C_{0}-C_{1}\right) * V_{\text {solution }}}{m_{\text {adsorbent }}}=[\mathrm{mg} / \mathrm{kg}]
$$

Further the adsorption isotherms were constructed for the 1 st and the 24th hour of contact of the adsorbent with the adsorbate.

\section{Results and Discussion}

The reactivity of diatomite, like that of synthetic amorphous silica, is internally related to the presence of active sites on its surface. Reactive sites not only determine the charge, acidity, solubility, and hydrophilicity of the surface, but are also sites of grafting and ligand exchange reactions. So, they largely determine the properties of diatomite-related products.
They have a macroporous structure, only $10-15 \%$ of the total pore volume are pores with a radius of 3-40 $\mu \mathrm{m}$ $[11,16,17]$.

Natural minerals do not have sufficient sorption properties for wastewater treatment. To increase this ability, they are modified chemically or thermally. In our experiment, activation was carried out with acid, alkali, and thermally.

Best results were obtained with alkali and acid treatment. Upon alkaline activation, unstructured amorphous silicon dissolved, which released an additional amount of hydroxyl groups and increased the number of active sorption centers. This fact is consistent with data $[12,14,16]$. The minimum contact of the adsorbent with the adsorbate was 1 hour. The graphs of the obtained relationships are shown in Fig. 1.

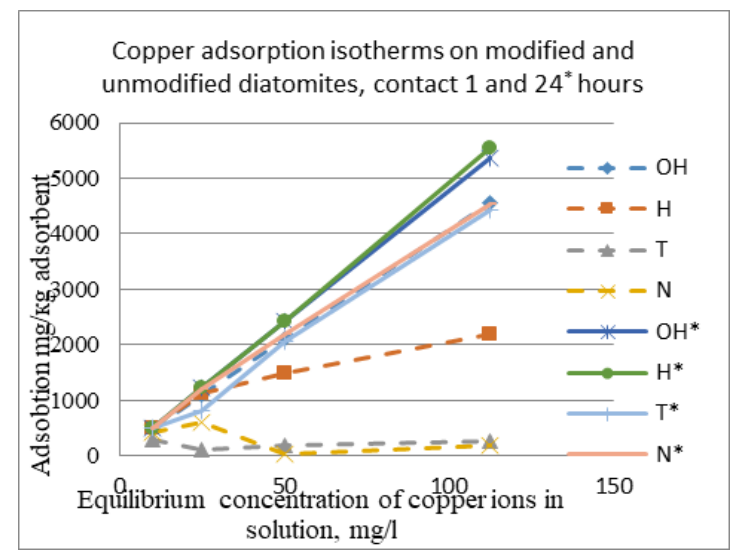

Fig. 1. Sorption capacity of the studied diatomite samples while extracting of $\mathrm{Cu}^{2+}$ ions from the model solution.

Acid activation dissolves iron compounds, releases micro- and nanopores and results in an increased sorption activity $[11,15,22]$, but adsorption equilibrium is reached much more slowly (Fig. 1).

Natural diatomite has a high sorption capacity for $\mathrm{Cu}^{2+}$ of low adsorbate concentrations, and an increase in the $\mathrm{Cu}^{2+}$ concentration in solutions leads to a decrease in sorption capacity. This is noted in case of minimal contact time (table 1). 
Table 1. Diatomite adsorption (A) and degree of absorption ( $\boldsymbol{\alpha}$ ) for copper ions $\mathrm{Cu}^{+2}$, adsorbent mass is $0.002 \mathrm{~kg}$, contact time is 1 hour, solution volume $\mathrm{V}=0.1 \mathrm{~L}$.

\begin{tabular}{|c|c|c|c|c|}
\hline \multirow{2}{*}{$\begin{array}{l}\text { Type of diatomite } \\
\text { modification }\end{array}$} & \multirow{2}{*}{$\begin{array}{l}\mathrm{C}_{0} \\
(\mathrm{mg} / \mathrm{L} \\
)\end{array}$} & 1 hour & 1 hour & \multirow{2}{*}{$\begin{array}{l}1 \\
\text { hour } \\
\alpha, \%\end{array}$} \\
\hline & & $\begin{array}{l}\mathrm{C}_{1} \\
(\mathrm{mg} / \mathrm{L})\end{array}$ & $\begin{array}{l}\text { A } \\
(\mathrm{mg} / \mathrm{kg})\end{array}$ & \\
\hline 1. Alkaline $(\mathrm{OH})$ & 10.0 & 0.7564 & 462.18 & 93.2 \\
\hline 2. Acidic $(\mathrm{H})$ & 10.0 & 0.0079 & 499.64 & 99.9 \\
\hline 3. Thermal (T) & 10.0 & 4.4416 & 277.92 & 55.0 \\
\hline 4. Natural (N) & 10.0 & 1.5324 & 432.38 & 84.6 \\
\hline 1. Alkaline & 25.0 & 2.92 & 1104.0 & 88.3 \\
\hline 2. Acidic & 25.0 & 2.52 & 1124.0 & 89.9 \\
\hline 3. Thermal & 25.0 & 22.6 & 120.0 & 9.9 \\
\hline 4. Natural & 25.0 & 13.12 & 594.0 & 45.9 \\
\hline 1. Alkaline & 50.0 & 7.588 & 2120.6 & 84.0 \\
\hline 2. Acidic & 50.0 & 20.292 & 1485.4 & 59.4 \\
\hline 3. Thermal & 50.0 & 46.092 & 195.4 & 7.4 \\
\hline 4. Natural & 50.0 & 49.251 & 37.45 & 1.4 \\
\hline 1. Alkaline & 112.7 & 21.52 & 4559.0 & 80.9 \\
\hline 2. Acidic & 112.7 & 69.05 & 2182.6 & 38.7 \\
\hline 3. Thermal & 112.7 & 107.55 & 257.5 & 5.1 \\
\hline 4. Natural & 112.7 & 132.55 & 185 & 0 \\
\hline
\end{tabular}

After alkaline and acidic modifications, diatomites have approximately equal adsorption capacity and degree of HMI absorption. This was noted during prolonged contact $(24 \mathrm{~h})$, in contrast to natural and thermally modified diatomite (Table 2). So, alkaline and acidic treatment of diatomite can be suggested to be used for the absorption of not only copper but other metals (lead, cadmium).

Table 2. Diatomite adsorption (A) and degree of absorption ( $\boldsymbol{\alpha})$ for copper ions $\mathrm{Cu}^{+2}$, adsorbent mass is $0.002 \mathrm{~kg}$, contact time is 24 hours, solution volume $\mathrm{V}=0.1 \mathrm{~L}$.

\begin{tabular}{|c|c|c|c|c|}
\hline \multirow{2}{*}{$\begin{array}{ll}\text { Type } & \text { of } \\
\text { diatomite } & \\
\text { modification } & \end{array}$} & \multirow[t]{2}{*}{$\begin{array}{l}\mathrm{C}_{0} \\
(\mathrm{mg} / \mathrm{L})\end{array}$} & $\begin{array}{l}24 \\
\text { hours }\end{array}$ & $\begin{array}{l}24 \\
\text { hours }\end{array}$ & \multirow{2}{*}{$\begin{array}{l}24 \\
\text { hours } \\
\alpha, \%\end{array}$} \\
\hline & & $\begin{array}{l}\mathrm{C}_{1} \\
(\mathrm{mg} / \mathrm{L})\end{array}$ & $\begin{array}{l}\text { A } \\
(\mathrm{mg} / \mathrm{kg})\end{array}$ & \\
\hline 1. Alkaline $(\mathrm{OH})$ & 10.0 & 0.0241 & 498.79 & 99.7 \\
\hline 2. Acidic $(\mathrm{H})$ & 10.0 & 0.00105 & 499.95 & 99.9 \\
\hline 3. Thermal (T) & 10.0 & 0.0450 & 497.75 & 99.5 \\
\hline 4. Natural $(\mathrm{N})$ & 10.0 & 0.0295 & 498.53 & 99.7 \\
\hline 1. Alkaline & 25.0 & 0.428 & 1228.6 & 98.3 \\
\hline 2. Acidic & 25.0 & 0.238 & 1238.1 & 99.1 \\
\hline 3. Thermal & 25.0 & 8.81 & 809.5 & 67.7 \\
\hline 4. Natural & 25.0 & 0.75 & 1212.5 & 96.9 \\
\hline 1. Alkaline & 50.0 & 1.46 & 2427 & 97.1 \\
\hline 2. Acidic & 50.0 & 1.44 & 2428 & 97.1 \\
\hline 3. Thermal & 50.0 & 8.81 & 2059 & 82.4 \\
\hline 4. Natural & 50.0 & 5.93 & 2203 & 88.1 \\
\hline 1. Alkaline & 112.7 & 5.17 & 5376.5 & 95.4 \\
\hline 2. Acidic & 112.7 & 1.66 & 5552.0 & 98.5 \\
\hline 3. Thermal & 112.7 & 24.59 & 4433.5 & 78.0 \\
\hline 4. Natural & 112.7 & 22.14 & 4528.1 & 80.3 \\
\hline
\end{tabular}

Taking into account that galvanic wastes containing copper, cadmium, and other HMIs have a $\mathrm{pH}$ significantly less than 7 , it can be assumed that acidactivated diatomite will have a higher adsorption capacity compared to all other types of modification. The active centers of alkaline diatomite, due to neutralization by acidic effluents, are likely to be neutralized and may lose their activity.

\section{Conclusion}

Analysis of the results obtained allows us to conclude that chemically activated (by acid and alkali) diatomite, in comparison with thermally activated and natural, has a high sorption capacity for HMI. For acidic galvanic wastewater, acidic modification of diatomite with prolonged contact of the adsorbent with the adsorbate is applicable. Chemically modified sorbents are characterized by high recovery rates from $80 \%$ to $99 \%$ (depending on the initial concentration), and can be recommended for the treatment of highly concentrated wastewater containing heavy metals.

\section{References}

1. Politaeva N., Bazarnova Y., Smyatskaya Y., Slugin V., Prokhorov V. (2017). Journal of Industrial Pollution Control, 33(2), P. 1617-1621.

2. C. Femina Carolin, Mu. Naushad, P. Senthil Kumar A. Saravanan, G.Janet Joshiba Journal of Environmental Chemical Engineering, Volume 5, Issue 3, (2017)- 2799 p.

3. Sean T.McBeath, Adel Hajimalayeri, Saad Y.Jasim, Madjid Mohseni/Journal of Water Process Engineering, Volume 40, (2021), 101983

4. Atamanova O.V., Tikhomirova E., Koshelev A., Istrashkina M., Politayeva N., Podolsky A., Wastewater treatment of industrial enterprises via adsorption method, IOP Conf. Series: Earth and Environmental Science, 337 (2019) 012010.

5. Chengyu Duan, Tianyu Maa, Jianyu Wanga, YanboZhouab/Journal of Water Process Engineering, Volume 37,(2020), 101339

6. Sarthak Gupta, S.Sireesha, I.Sreedhar, Chetan M.Patel, K.L.Anitha /Journal of Water Process Engineering, Volume 38, (2020), 101561

7. Shweta Wadhawan, Ayushi Jain Jasamrit, Nayyar Surinder, Kumar Mehtab H:Journal of Water Process Engineering, Volume 33, (2020), 101038

8. Mona Abbasi, Edwin Safarib, Majid Baghdadia, Mehran Janmohammadi/Journal of Water Process Engineering, Volume 40, (2021), 101961

9. Atamanova O.V., Tichomirova E.I., Politayeva N.A., Podolsky A.L., Istrashkina M.V., Innovative technologies for industrial wastewater treatment, IOP Conf. Series: Earth and Environmental Science, 288 (2019)

10. L. Schlapbach and A. Züttel, Nature 414, 353 (2002). J. Jin, C. Zheng \& H. Yang Functional Materials Letters Vol. 7, No. 3 (2014)

11. Y. Zhang and H. M. Yang, Funct. Mater. Lett. 6, 1350013 (2013).

12. H. T. Fang et al., J. Phys. Chem. C 112, 5790 (2008).

13. J. Jin et al., Phys. Chem. Miner., doi: 10.1007/s00269-013-0651-z (2013). 
14. Z. Wang and R. T. Yang, J. Phys. Chem. C 114, 5956 (2010).

15. Ol'shanskaya L.N., Sobgaida N.A., Tarushkina Yu.A., Stoyanov A.V. (2008). Chemical and Petroleum Engineering, 44(7-8), P. 475-479

16. H. Frost, T. Düren and R. Q. Snurr, J. Phys. Chem. B 1109565 (2006)

17. Mai WX, Meng H: Integr Biol 2013, 5: 19-28.

18. B. Panella et al., Adv. Func. Mater. 16, 520 (2006).

19. Breese R (1994) Diatomite. In: Carr DD (ed) Industrial minerals and rocks. SMME, Englewood, pp 397-412

20. Politaeva N.A., Slugin V.V., Taranovskaya E.A., Soloviev M.A., Zakharevich A.M. (2017). Izvestiya Vysshikh Uchebnykh Zavedenii, Seriya Khimiya i Khimicheskaya Tekhnologiya, 60(7), P. 85-90.

21. Politaeva N.A., Olshanskaya L.N., Ovchinnikov F.A., Sverguzova S.V. (2019). IOP Conference Series: Earth and Environmental Science, 288(1)

22. P.V. Smirnov, A.O. Konstantinov H.J. Gursky Environ Earth Sci., 76, 682 (2017)

23. Tikhomirova E.I., Plotnikova O.A., Atamanova O.V., Istrashkina M.V., Koshelev A.V., Podolsky A.L., The use of multicomponent adsorption filters in water purification systems and luminescent control of ecotoxicant content // Theoretical and Applied Ecology, (2019) №1. P. 73-81

24. K. S. W. Sing et al., Pure Appl. Chem. 57, 603 (1985). 